\title{
Construction Innovation of Building Complex in Maritime Service Agglomeration Area-Case Study of Shanghai
}

\author{
Pengcheng Wu ${ }^{1}$, Xuefeng Wang ${ }^{2, *}$, Jiawei Ge ${ }^{1}$ \\ ${ }^{1}$ Institute of Logistics Science \& Engineering, Shanghai Maritime University, Shanghai, China \\ ${ }^{2}$ College of Transport \& Communications, Shanghai Maritime University, Shanghai, China
}

\section{Email address:}

13818991239@139.com (Pengcheng Wu),wangxf@shmtu.edu.cn (Xuefeng Wang)

${ }^{*}$ Corresponding author

\section{To cite this article:}

Pengcheng Wu, Xuefeng Wang, Jiawei Ge. Construction Innovation of Building Complex in Maritime Service Agglomeration Area-Case Study of Shanghai. American Journal of Civil Engineering. Vol. 5, No. 3, 2017, pp. 132-140. doi: 10.11648/j.ajce.20170503.12

Received: February 11, 2017; Accepted: March 3, 2017; Published: March 15, 2017

\begin{abstract}
Agglomeration and building complexes are two mainstreams in modern urban development, planning and construction. The combination of agglomeration theory and building complex theory is proved to be feasible and useful through function analysis of Shanghai Maritime Service Agglomeration (SMSA) area. The findings point out that construction innovation of building complexes should comply with the integral demand of talents, companies and government. In addition to external scale effect, cost reduction, talents attraction and other agglomeration effects, function innovation of SMSA is analyzed and investment is made in four main aspects as comprehensive maritime services, resource \& energy saving, environment-friendly \& green transformation and environment adaptive yacht harbor operation. The assessment and discussion on the construction project witnessed a great success that social and economic benefits are abundant. The experience of SMSA is summed up to provide theoretical and practical reference for the construction of other building complexes and agglomeration areas.
\end{abstract}

Keywords: Maritime Services, Agglomeration, Construction Innovation, Building Complex

\section{Introduction}

Because of its leading role to the economy, industrial agglomeration has attracted much attention in many fields of social activities. From the agglomeration theory in classical economics to the cluster theory in modern economics and management theory, the role of agglomeration has been developed by leaps and bounds. [8, 12, 17]

Since the nineties of last century, the concept of maritime cluster is widely spread in Europe. Due to the recognition of the impact of concentration on the European shipping industry and economy, Netherlands, in 1997, set up the Dutch Maritime Cluster (NML) started to study the maritime cluster systematically. Researches about the cluster of maritime service are becoming more in-depth over time. However, most of the studies have focused on the content, evolution, classification, characteristics and patterns of the maritime service cluster itself. [1, 5-6, 9-10, 15-16, 20] The physical concrete of cluster, for example, the building of the cluster area is left behind. As the carrier of cluster, the physical building plays an important role in promoting the agglomeration effect. Therefore, the physical building in the agglomeration area should be developed and constructed according to the agglomeration theory and corresponding demand.

In recent years, the concept of building complex has become the mainstream of commercial real estate, since its birth, building complex has developed to be a light spot in construction and planning of world's major cities and has brought its superiority in urban economic, social and cultural development. As a new form of commercial space, the interaction between urban complex and its agglomeration area can further enlarge agglomeration effect [3], but the academic researches on building complex are relatively poor and lacking in appropriate theoretical support.

This article intended to provide theoretical and practical support for the planning and construction of building complex in agglomeration area through the combination of agglomeration theory and building complex theory, and to 
sum up the experience of Shanghai Maritime Service Agglomeration (SMSA) area in analyzing its function and construction innovation.

\section{Background of the Case Study}

The construction of the Shanghai maritime service cluster is a systematic planning and comprehensive deployment of the 'International Financial Center and International Shipping Center'. [18] It requires Shanghai to integrate the port resources of Yangtze River Delta and to improve the layout of maritime service, thus becoming an international shipping center with the ability in allocating global shipping resources.

Throughout the experience of shipping centers in other countries and regions, the construction of well-known shipping centers such as London, New York and Singapore has undergone the transformation of old port districts and service upgrading. Given Shanghai's actual situation, the old port area named Huishan, located at the North Bund along the Huangpu River, is facing such a historical moment. (See Figure 1.

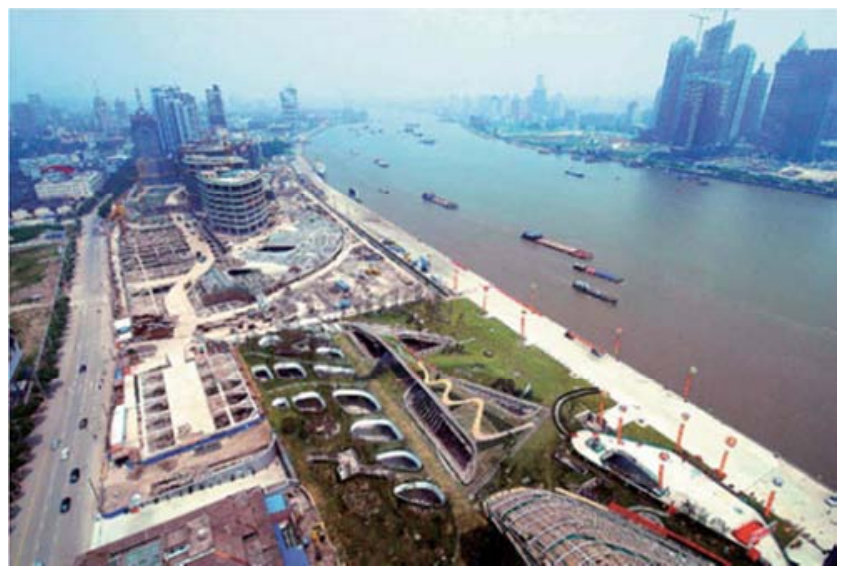

Figure 1. Huishan old port before transfprmation.

The long shipping history and deep industrial base of the North Bund is the cradle of modern shipping service industry. With the development and expansion of urban area, the port function of Huishan has shifted to its periphery and the corresponding infrastructure is obsolete that no longer meet the needs of modern maritime service industry. However, Huishan's irreplaceable landscape and water depth $(7 \mathrm{~m}$ in average) are unique geographical advantages in the development of SMSA. Therefore, in response to the construction of Shanghai international shipping center, Shanghai Municipal Transportation and Port Authority proposed the 'Initiatives on The Implementation of Accelerating The Construction of Shanghai International Shipping Center' and clearly pointed out the function planning of the Huangpu River along the old port area by converting Huishan into maritime service agglomeration area with shipping-based building complexes in strengthening its business and supporting functions.

Huishan old port area was originally the third loading and unloading area of Shanghai port, founded in December 1952, known as the Shanghai Port Huishan Loading and Unloading Company. Over the years, it has not only handled and transhipped millions of groceries, steel, construction materials and other bagged cargoes, but also is responsible for a certain number of passenger tasks. The terminal is no longer in operation since 2003 and gradually demolished to the flat for open space at the beginning of 2009. The construction and transformation project includes five commercial buildings, namely $13 \#$ to $17 \#$ with a total area of 205,000 square meters, see Figure 2.

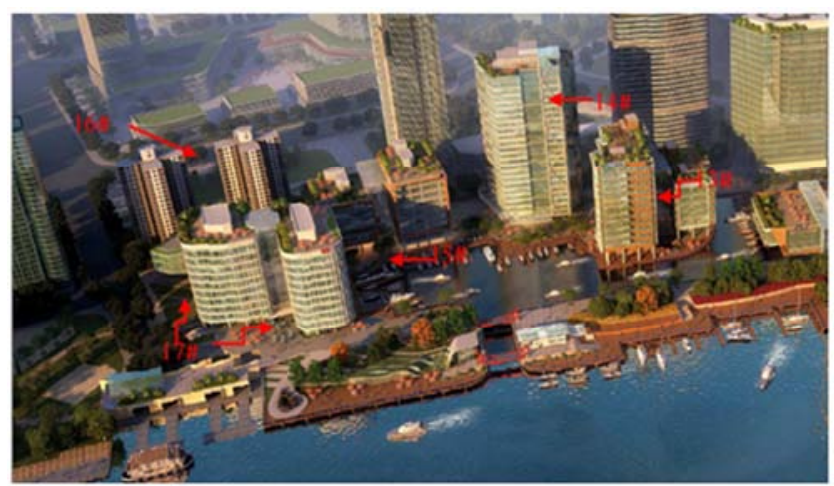

Figure 2. Huishan Project Outline.

\section{Function Analysis}

In the process of constructing the SMSA area, function analysis is the key factor to its success. The requirements of relevant parties such as talented people, enterprises and government should be taken into consideration so that corresponding functions can be targeted and designed with the full advantage of Shanghai's location and supporting policies. This section put emphasis on the characteristics of maritime service agglomeration area and analyzed the requirements of relevant parties respectively, that is, to determine the functions and conditions of SMSA according to actual demand and driving power of agglomeration. Five basic functions were summarized and induced as following:

\subsection{Function One: Economies of Scale for Enterprises}

The economies of scale of enterprises are mainly composed of the internal economies of scale brought by mass production of single enterprise and the external economies of scale produced by the division of labor among different enterprises. From the perspective of internal economies of scale, companies tend to gather at the consumer side or the origin place [8], resulting in increased business volume and reduced marginal cost of production, which may further promote the scale expansion of enterprises and reach economies of scale inside the company. Take the international freight forwarding service as an example, there are hundreds of international freight forwarders gathered in Dongdaming Road, Dalian Road and Yangshupu Road in SMSA area, which made them geographically closer to the customers than their counterparts outside the area. Customers as liner shipping companies come here for its reputation 
which increase the probability of business access and the scale expansion of the company driven by increment of its business volume. Therefore, the bargain power was enhanced with lower agreement tariffs, reducing production costs and reaching economies of scale. Similarly, the external economies of scale mainly reflect the decline in the cost, the difference is that such costs can be seen as the inner cost of the entire industry, which may cause the strengthening of intra-industry cooperation and lead to increasing returns to scale. Moreover, other ancillary industries that serve the industry will also reach economies of scale because of the increased demand from the industrial agglomeration, for example, high infrastructure spending is shared by more enterprises, which in turn results in more low-cost service, and further reduce the operation and production costs. So the construction of commercial buildings in SMSA area is particularly important, which can reduce the investment and expenditure of enterprises in public infrastructure. After all, the original intention of agglomeration is the demand for cost control.

Therefore, the planning of maritime service agglomeration area should mainly consider the construction of commercial buildings or complexes so as to form spatial concentration and provide enterprises with a good business environment and infrastructure service.

\subsection{Function Two: Technology and Knowledge for Innovation}

As per agglomeration theory, agglomeration will bring out 'knowledge spillovers', that is, the gathering of enterprises geographically will accelerate the flow of new technologies and knowledge through formal and informal organizational exchanges, making the area easier for enterprises to grasp the latest intelligence with rapid response at the same time, which also increased the competition among enterprises in agglomeration area, thus driving enterprises to technological innovation. As a producer service, the characteristics of maritime service act like a bridge in the entire system for transmission and dissemination of external knowledge, facilitating enterprises to participate in a variety of innovation-related activities, promoting knowledge flow and integration within the innovation system. Moreover, due to its close connection with the manufacturing industry and other service industries, the maritime service enterprises can also integrate the innovative concepts from internal departments, external customers and other intermediary organizations and research institutions, so as to form a new innovation. [2] For example, shipping finance is a demand-oriented innovative business cooperation model, based on the knowledge and information exchange among companies, customers and exchanges. Compared with the external single enterprise, companies in agglomeration area have better communication on information, knowledge exchange and interactive learning environment, thus making innovation and achievements easier. However, on the other side, the new methods of innovation are more easily to be imitated so that companies are forced to keep innovating.
Therefore, the construction of maritime service agglomeration area should consider the support and cultivation of innovation ability, creating a business condition that is conducive to business exchanges and cooperation with a fair and competitive environment institutionally.

\subsection{Function Three: Access to Professional Services}

The synergetic effect of industrial agglomeration and division of labor can further refine the division of labor in the agglomeration area, which leads to specialized production and service. Relatively, the enlarged demand for professional services will encourage the agglomeration of professional services companies in return. Maritime services are based on and derived from the fundamental transportation services, especially those auxiliary services around physical transportation such as agency, shipping brokerage and ship inspection. Companies in agglomeration area will have amenity in access to professional services for local shipping service enterprises. At the same time, the cooperation and communication among enterprises can be enhanced through formal and informal organization and exchange activities. For example, the cooperation and communication between the liner shipping companies and the neighboring shipping agencies will enable the shipping agent to have a clear understanding of the service category required by its customers, so as to provide 'personalized' service and ensure proper disposal of the ship which can hardly be found in ordinary shipping agencies, especially when it comes to emergency circumstances, the degree of their spatial location and understanding of each other plays an important role in the on-site collaboration of both parties. In addition, these specialized service are interlocked and serve the overall efficiency of transport, such as the great impact of administrative service center on the efficiency of freight forwarders in custom declaration and inspection.

Therefore, the construction of maritime service agglomeration area should consider the cultivation of professional services, including the construction of related industries and administrative departments.

\subsection{Function Four: Regional Economic and Social Benefits}

Studies on producer service shew that agglomeration will bring along regional economic development and generate enormous economic and social benefits. [2] From the view of its direct effect on economy, agglomeration has a significant impact on regional Gross Domestic Product (GDP) and employment. The indirect effect on society said that agglomeration is helpful to improve the regional environment and to promote the regional reconstruction and redevelopment. [4]

With respect to its contribution on regional economy, as mentioned above, the maritime service industry agglomeration brings economies of scale into individual enterprises, which is the integral whole of the industrial economy. Therefore, from the microscopic aspect, 
agglomeration plays a leading role on the development of regional economy. On the other hand, according to the empirical analysis of the maritime service industry, agglomeration serves the regional GDP and fiscal revenue through the former multiplier effect, consumption multiplier benefits and self-development. Additionally, in the process of industrial structure change, employment will stagnate or even decline due to the relocation of manufacturing industry, then the producer service industry will become an important supplement to create employment opportunities. So the agglomeration of maritime service industry becomes the main sector to absorb urban employment, undertaking the surplus labor force during the transformation of urban industrial structure.

In terms of social benefits, the maritime service cluster is located in commercial building complexes with perfect hardware conditions as excellent information and communication infrastructures, elegant environment, convenient transportation and service facilities. So the impact of maritime agglomeration can be extended to social section through the construction of low-carbon innovation system, which contains two implications: First, the maritime service cluster relies on modern commercial building complexes to achieve resource recycling, energy saving and emission reduction through low-carbon innovation technically and systematically; Second, the low-carbon symbiotic relationship between maritime service and other regional producer services can promote regional emission reduction on a whole scale. For example, the structure adjustment in maritime service industry on reducing high-pollution and low-end services while providing more value-added services will promote the optimization and upgrading of the structure change.

Therefore, the construction of maritime service agglomeration area should take into account the requirements of regional economic and social benefits for the purpose of employment increment and environmental protection.

\subsection{Function Five: Attraction on High-End Talents, International Conglomerates and Institutions}

The agglomeration of maritime service brings together high-end talents, international conglomerates and well-known institutions. The essence of industrial agglomeration is the agglomeration of productive forces. Human resources, as an important component, depends on the spatial distribution of productive forces. So the concentration of enterprises in the same or related industries in certain areas will inevitably lead to the concentration of human resources at this region, which is mainly manifested in the specialization of labor market as a major feature. Due to the gathering of conglomerates in this region, a high demand for specialized labor occurs and causes the accumulation of human resources. The agglomeration area provides more job opportunities for employees. In the meantime, it is easier for employers to find professional labors meeting the needs of production through sharing the labor market. A large number of labor demand will also promote professional labor training institutions and affiliated industries. This is the primary form of human resources agglomeration. When the maritime service industry developed to a certain extent, that is, the emergence of high-end maritime service, the demand for high-end talents will incur the accumulation and optimization of human resources structure. With the deepening of such division, the demand for high-end maritime service continues to increase, so as for the talents. Coupled with the improvement of commercial and residential environment, more senior talents are attracted to move in, forming different levels of human resources and optimization of its structure. [16]

Similarly, conglomerates and institutions relies heavily on local business and policies. The SMSA area gathered enormous resources range from business and organization level to human resources level, thus creating a brilliant business environment. What's more, when local government decided to set up industrial agglomeration area, preferential and supporting policies were always issued to attract talents from conglomerates and institutions. For example, talents selected in Shanghai's 'Thousand Talents Program' will enjoy financial support, household registration, housing and medical security, convenient customs clearance and priority placement for their children.

Therefore, the construction of maritime service agglomeration area should think over its attraction to high-end talents, international conglomerates and institutions, followed with preferential and supporting policies. The construction of complexes should focuses on its convenience and eco-friendliness for residents and businesses accordingly.

\section{Construction Innovation}

The construction innovation of the building complex in SMSA area is based on its function analysis. The demand for shipping building complex can be extracted and summarized as demand of enterprises, government and talents. So the concepts of service, talent and green are introduced and hypostatized into building construction respectively. As shown in Figure 3, the original functions are converted to the demand for commercial area deployment, supporting business environment, energy saving $\&$ emission control and talents. Take 'Economies of Scale' as an example, Commercial area or business buildings are required as their office, while supporting business environment can achieve inter-enterprise exchanges and cooperation. Moreover, the concept of energy-saving \& emission control is conducive to reduce operating costs and achieve companies' social responsibility via environmental protection. Based on the idea and construction content, combined with the characteristics of shipping, four kinds of construction innovation were introduced into the function design of building complexes as comprehensive maritime services, resource \& energy saving, environment-friendly \& green transformation and environment adaptive yacht harbor operation, complying with the Huishan old port reconstruction project. 


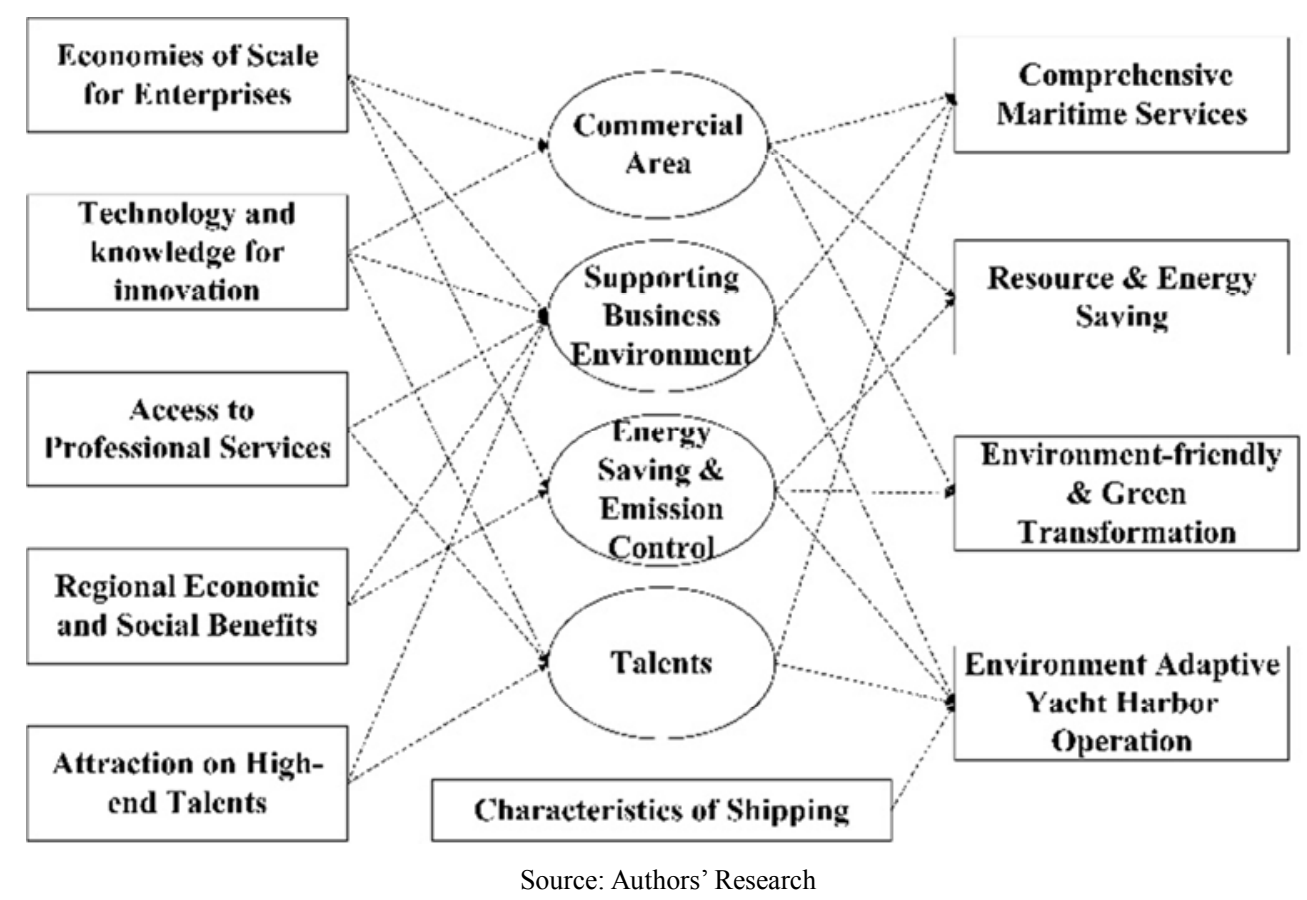

Figure 3. Hypostatization of Function Analysis.

\subsection{Comprehensive Maritime Services}

The function of comprehensive maritime services is mainly reflected in the construction of commercial building complexes, supporting business environment and talent or personnel cultivation. The transformation of Huishan old port is taken as the starting point to cooperate with Shanghai international maritime service center, which embodies the core function and scale effect of Shanghai maritime service industry to achieve the goal of agglomeration. To this end, the transformation aimed to strengthen the business and supporting functions, and was conducted to form classic building complexes in line with the theme of shipping along the Huangpu River, including modern office and commercial areas. The functional orientation of this area include all facilities as offices, businesses, conferences, hotels and apartments, etc.

Huishan old port is located in the North Bund, traditionally a place with rich resources of shipping. In recent years, the construction of the 'North Bund Maritime Street' has achieved remarkable results that shipping companies are concentrated with shipping agents, freight forwarders, storage and transportation companies, logistics companies, and other related corporations in one place. It is also adjacent to Shanghai Shipping Exchange (SSE), which set up a fair and just trading environment in regulating the shipping market transactions and prices. In addition, the construction of the international passenger center for the cruise industry will drive the redevelopment of maritime service at surrounding areas of Huishan. The transformation of Huishan old port then could enhance supporting infrastructures and integrate comprehensive maritime services, so as to stimulate the regional vitality with a multi-functional business community containing transactions, shipping offices and so on.

Thus far, the transformation then started from its color, shape, interior decoration, building energy efficiency standards and other corresponding alterations so that the building can greet the SSE, which is regarded as a representative of SMSA area. On the other hand, the core commercial office building could attract and settle related companies, especially the world's largest liner shipping companies, logistics enterprises, freight forwarding companies, cruise liners, maritime law offices and other institutions, striving to foster a mature maritime service market with import \& export logistics service and international passenger service.

This new building also highlighted its port function and service environment that inspection and quarantine, customs, border security and other supervision departments were gathered together with finance, insurance, legal advice and other shipping-related services in this building, aiming to set an one-stop portal on international shipping.

In order to further attract more multinational companies, and to promote convergence of shipping trade, shipping finance, shipping insurance and other shipping elements, while conforming to the old port environment and Shanghai's developing strategy, the construction put forward the combination of industrial restructuring. Docks, factories and warehouses were cleared or relocated, replaced by diversification functions as residential, working, cultural, leisure and tourism areas, changing its role from the industrial domain to modern service oriented.

\subsection{Resource \& Energy Saving}

The original Shanghai port building is far away from its 
construction day, nearly half a century, whose facilities are out of date whether in hardware or software, especially the energy efficiency standard that has been unable to keep up with the current requirements of modern mansion as an international maritime service center. So it is an urgent need for the old building to conduct resource \& energy saving, complying with current regulation and normal standard.

According to the comprehensive development of North Bund area and computer simulation [21], the transformation fell into two parts, the podium and the main building respectively. First, the podium was removed and rebuilt with the floors and facade adjusted. Functions of SSE was incorporated into its podium and lower floors. Second, the internal layout and facade were redesigned that part of the basement, the third floor of the podium and the forth to fifth floors of the main building were planned to locate the new Shipping Exchange.

(1) Materials and Resources

In order to reduce all building materials resources, energy consumption and environmental pollution, it is forbidden to use the materials and products that are restricted or eliminated in the 'Catalog of Eliminating Backward Production Capacity, Process and Product'. [14] The consumption of natural and mineral resources was strictly controlled for the protection of ecological environment. In practice, only durable and water-efficient products were considered while using industrial waste as raw materials, insulation materials, high-performance cement and concrete instead of materials as solid clay brick that may cause trouble to arable land.

In terms of environmental impact, supervisory control was expanded to the whole supply chain from the transportation to the execution of building materials like reducing the impact of solid waste on surrounding environment, maximizing recycling of resources and optimizing the waste disposal program.

(2) Water Resources System

To achieve sustainable development and utilization of water resources, concepts as advanced management was embedded through water using plan, rational and efficient water balance programs to save water and achieve optimal allocation of water resources.

(3) Energy System

With respect to the efficiency of energy utilization, the heating and air conditioning heat source selection were optimized, while the efficiency of transmission and distribution system were improved, fully considering the occupation of space. Next, the measurement and monitoring system was strengthened to improve the proportion of renewable energy use, reducing the negative impact of energy consumption on the environment. What's more, the use of advanced and efficient, low-pollution energy supply system, non-renewable resources might save energy and resources to the greatest extent.

(4) Indoor Environment Quality

To ensure adequate indoor air quality, meet the health requirements and the provision of adequate air volume, the fresh air intake system was reasonably designed, preventing improper ventilation caused by poor air quality.

\subsection{Environment-Friendly \& Green Transformation}

Environment-friendly \& green transformation primarily depends on the optimization of environmental protection of the buildings. The key factor is to increase the investment in green system. During the process of reconstruction, the idea of green transformation was actively explored and applied, aiming to well integrate the transformation with better energy conservation, specifically embodied in the following aspects:

1) Outdoor Environment

To increase the plot ratio of the agglomeration area, roof greening technology was introduced and applied on all the complexes with plants or those adaptive to the distinct seasons of Shanghai, which are chilly in winter and humid in summer, such as osmanthus, farfugium japonicum, orchid, Stipa, Hemerocallis, ophiopogon japonicus, camellia, so on so forth. The basements also used a variety types of permeable pavement as grassplot, pond and brick to enhance water retention, while reducing storm runoff.

2) Energy Conservation and Utility

The buildings are covered with curtain glasses and shading system, planting roof insulation technology and other energy-saving measures to cut down the load of air conditioning. And at the end of it, there is a variable air volume (VAV) air conditioning system that takes full advantage of the transitional seasons of enthalpy difference, using fresh air for self-cooling. Meanwhile, a carbon dioxide sensor and exhaust heat recovery system was set up to reduce fresh air handling loads.

The cooling and heating system is set with water source heat pump (WSHP) and ice storage. The cooling system uses water through the heat exchanger, cooled and pumped into the refrigerator for recycling. The heating system makes use of its location adjacent to Huangpu River, with WSHP host supply mode, the heat pump evaporator and water were separated through the heat exchanger, while adding glycol in the evaporator water cycle to ensure the safety of unfrozen liquid.

T5 fluorescent lamps, LED and other energy-saving lamps are used in the main functional areas of the building, such as offices and conference rooms. On the basis of illumination design standard, the lighting power density is lower than the target value stipulated in the 'Energy Efficiency Design Standard for Public Buildings'. [11] At the same time, the lighting of the official building has a programmable lighting control strategy based on personnel activity time and a solar induction control switch, which can automatically adjust the number of lumens of artificial lighting according to the natural illumination for energy saving.

3) Water-saving and Water Resources Utilization

During the transformation of the old port area in water planning, supply and drainage design, the characteristics of local water resources and climate are taken full account of. Sewage, waste water and rainwater are diverted to discharge so that the sewage will not pollute the recyclable water, while 
waste water and rainwater are reclaimed as raw water, and a special system is set up to collect and process them. A supporting system is designed with filter and disinfection facilities to protect water quality and safety. The pipeline applies a variety of measures to avoid pipe leakage, such as anti-rust materials, plastic lining technology, pressure test and irrigation test.

Rainwater and the recycled water system is treated as miscellaneous water (such as flushing, green irrigation and garage pavement and road sprinkling) after collection, storage and handling. The washing waste water, plenishing water of the harbor pool and roofing rainwater are separately collected into two regulating and sedimentation tanks for further treatment and then collected in the same clean water tank. The rainwater system recovers the roofing rainwater, which is relatively clean and can be recycled after simple precipitation, filtration and disinfection. The poor water quality of road rainwater causes high processing cost, so it is not considered in the rainwater collection system. Micro-sprinkler irrigation, drip irrigation and other efficient irrigation systems are used incorporating with the rain or humidity sensor and other automatic control devices to minimize the amount of irrigation water.

4) Materials Resource Utilization

The idea of material saving was integrated in the designing process of the building, in which the final construction drawing design is compared with that of similar projects so as to minimize the consumption of materials. In practice, civil engineering and decoration are integrated together, while indoor plane is made in a more flexible way.

The integration of civil engineering and decoration can fully reflect the designer's intent that strengthen the building's implication and integrity harmonically. At the same time, it is possible to unify the reservation of holes on the building components and of the embedded parts of the decoration surface layer in advance so as to avoid cutting and perforating the existing building components in the decoration and construction stage, ensuring the safety of the structure and reducing the construction waste. In the designing stage, it allows the architects to ensure that the adjustments on the size of the building as far as possible according to the size of the final decoration surface materials, thus maximizing the utilization of materials and saving decoration time and energy consumption.

More flexible utilization of indoor plane are convenient for office layout, especially for small business owners stationed after the construction, enabling the adjustments of layout and separation of office furniture. Walls for business unit are light steel keel gypsum board which have dismantled nodes so that it can be recycled when the tenant changes.

\subsection{Environment Adaptive Yacht Harbor Operation}

Environment adaptive yacht harbor operation is the consequence of involving the characteristics of shipping during the construction, interacting with the riverside culture, entertainment and leisure facilities for high-end shipping personnel so as to provide sightseeing, leisure and business appointment service. The yacht harbor is a double gate lock connecting the Huangpu River which allows fast and safe access for yachts. Given that the maximum flood flow rate of the Huangpu River is $21.42 \mathrm{~mm} / \mathrm{a}$ and its soft geology [19], the flood-prevention wall at the south side is combined with the water-front landscape, coming into several viewing platforms at different elevations varying with the original wharf. The west side linked with the international passenger center provides an open space for overall pattern. The detailed layout and planning are as following:

1) Large Underground Space

The yacht harbor was surrounded by the buildings at the west block of the old port, so it is designed to connect the east, north and west sides of the central building as a 'concave' shaped layout. During the vertical design of the yacht harbor, in order to ensure the hydrophilic effect, the design elevation of the port wall fits with the height of the base floor, while the baseboard meets the safe navigable depth. In addition, sufficient clearance is left for underground garages and commercial areas below the bottom floor of the harbor. So the structure of the yacht harbor, based on the underground structure roof as the foundation, is strictly designed and taken full account of the characteristics of its underground geography to ensure its waterproofness and safety.

2) Overall Arrangement of The Ship Lock

Due to the special environment of the yacht basin, whose exit is vertical to the direction of flow, the ship lock is deployed scientifically and rationally. For the convenience of access, the axis of the ship lock are arranged at the broadest place. For emergency collision, a navigation piers are set up at both upstream and downstream sides of the gate along with the front line of the old pier, while taking the low-seismicity of Shanghai into consideration. [7] On the other hand, maintenance platform, equipment room and bridges are also deployed respectively.

3) Arrangement of Waiting Berths

Before entering the port through the lock, in accordance with the relevant operating process, yachts need to be temporarily stationed at the waiting berths along the riverside until the appropriate hydrological conditions. Since the berths are arranged alongshore, the berthing pontoon should have sufficient safety distance from the upstream and downstream and should avoid the infrastructure of the gate and drain area. Therefore, the full type mode is applied in the arrangement.

4) Riverside Landscape

The construction process includs a riverside landscape project to facilitate the enjoyment of river view, and it is divided into several large landscape nodes connected with the platform step by step, maximizing the viewing angle.

5) Traffic Organization

The traffic organization for the harbor is planned to improve the access for yachts, yacht users and pedestrians at the same time, aiming to form a comprehensive transportation system. A moveable bridge is built on the top of the gate. When the yacht waiting for the gate, users can get into the building via the bridge and a platform connecting the 
harbor and the building. If there is no yacht inward or outward, bridges are closed and pedestrians are free to anywhere of the viewing platform, vice versa. Moreover, fire trucks, flood control and rescue vehicles, locks and other engineering maintenance car can get access to this part unimpededly.

\section{Assessment and Discussion}

The SMSA have achieved a series of success through the reconstruction of the old port area, not only in its social and economic benefits, but also have active influences on a micro level such as the construction of Shanghai Shipping Center, design innovation in water-based architecture and improvement for surrounding industries.

The building retrofit technology and energy-saving innovation technologies under the project have been duplicated and adapted to other four new buildings in SMSA area. After the reconstruction project, the Shanghai Port Building, now as the International Maritime Service Center, reached its design objectives: the building area increased by $21.2 \%$, or 8420 square meters; Energy saving rate reached $57.23 \%$ with the energy-saving demonstration area of 3.75 million square meters; Annual energy saving on electric quantity was 596,260.53 kWh; Annual $\mathrm{CO}_{2}, \mathrm{SO}_{2}$ and dust emission reductions came to 441.83 tons, 3.582 tons and 1.79 tons respectively. The five new buildings have been certified by BREEEAM of United Kingdom, the LEED of United States and China's Three Star Green Building, which is the first domestic complexes enjoying such honor simultaneously. The consumption test shew that those five new buildings could save 13,479,095 kWh of electricity and 162,099 tons of water per year. The 'Installation Structure and Construction Instruction of Clay Wall on Skyscrapers' applied in the construction has a national invention patent (invention patent number: ZL201210155455.1) and provide reference for the installation on other high buildings.

Economically, the construction contributed significantly to the corporate profit and government tax revenue, see Table 1 below.

Table 1. Economic Benefit of the International Maritime Service Center.

\begin{tabular}{lll}
\hline Year & Additional Profit (MS) & Additional Tax (M\$) \\
\hline 2012 & 191.45 & 31.11 \\
2013 & 205.95 & 116.26 \\
2014 & 855.72 & 85.62 \\
2015 & 1081.98 & 132.17 \\
2016 & 1414.12 & 159.43 \\
\hline
\end{tabular}

Source: Shanghai International Shipping Service Development Co., Ltd.

On the micro level, the SMSA drove its external environment in following aspects:

(1) Promotion on The Construction of International Shipping Center

The project is located in the core area of the North Bund, clustering major port authorities, international shipping companies and effectively enhancing the core function and scale effect of international maritime service. It is the important component of International Shipping Center

(2) The Transformation and Upgrading of The Old Port

The implementation of this project has directly promoted the transformation and upgrading of the old port area from a single function on transportation and storage to a comprehensive function of modern maritime service. The adjustment and optimization on the port achieved sustainable development of the port city relationship.

(3) Design Innovation in Water-based Architecture

The utilization of large-scale yacht harbor on the top of underground space, vertical ship lock and yacht lifting technology model simultaneously is the first attempt in water-based architecture, accumulated a wealth of technical experience for the hydraulic construction.

(4) Application of Green Technology

According to the characteristics of energy consumption and environmental control of commercial buildings, this project adopted a green building technology system suitable for local conditions, including regional water treatment systems based on recycled rainwater and harbor water, which have a great reference value for the future development of the same type of commercial buildings.

(5) Construction of the Riverside Landscape

The SMSA area is located at the most beautiful downtown area along the Huangpu River. So the construction of riverside landscape with river view, green land and harbor view helps to improve the people's living quality and favor of city sightseeing.

(6) Rise of Yacht Industry in the Huangpu River

The project features a yacht harbor, which is the largest yacht base in the center of the Huangpu River, and has laid a solid foundation for the development of the yacht industry along the Huangpu River.

\section{Conclusion}

Agglomeration and building complexes are two mainstreams in modern urban development, planning and construction. The combination of agglomeration theory and building complex theory is proved to be feasible and useful through function analysis.

The case of Shanghai shows that construction innovation of building complexes should comply with the integral demand of talents, companies and government. In addition to external scale effect, cost reduction, talents attraction and other agglomeration effects, function innovation of SMSA is analyzed and investment is made in four main aspects as comprehensive maritime services, resource \& energy saving, environment-friendly \& green transformation and environment adaptive yacht harbor operation.

The assessment and discussion on the construction project witnessed a great success that social and economic benefits of the project are abundant. The experience of SMSA is referential and can be generalized theoretically and practically to the construction of other building complexes and agglomeration areas. 


\section{Acknowledgements}

We would like to thank Shanghai International Shipping Service Development Co., Ltd for helping us arrange and coordinate the interviews with different departments in SMSA. This study is sponsored by the Shanghai Municipal Government (2015-YJ-E03, 2016-YJ-E02) and Ministry of Transport (2015322268570).

\section{References}

[1] Fisher Associates. (2004) The Future of London's Maritime Service Cluster: A Call for Action. London: Corporation of London.

[2] Guo xiaoyin. (2013). A Research on Regional Agglomeration of Producer Services and Innovation [M]. Beijing: Economic Science.

[3] Hu, M. Z., Fan, Y. H., \& Zhao, Q. Q. (2011). A study of HOPSCA development under the intensive land use. In Applied Mechanics and Materials (Vol. 71, pp. 589-593). Trans Tech Publications.

[4] Humphreys, B. R., \& Zhou, L. (2013). Sports facilities, agglomeration, and urban redevelopment (No. 2013-4).

[5] Langen P W. (2002) Clustering and performance: the case of maritime clustering in The Netherlands [J]. Maritime Policy \& Management, 29 (3): 209-221.

[6] Lam J S L, Zhang W. (2011) Analysis on Development Interplay between Port and Maritime Cluster[C]//First International Workshop on Port Economics, National University of Singapore (December 5-6, 2011).

[7] Liu, W., \& Liu, Y. (2012). Trend Prediction of Seismicity in Lower Reaches of Yangtze River-Yellow Sea (YY) Seismic Belt in 2011-2020. Geosciences, 2 (3), 39-50.

[8] Marshall A. (1890) Principles of economics: An introductory volume [M]. London: Macmillan.

[9] Masato Shinohara. (2010) Maritime cluster of Japan: implications for the cluster formation policies, Maritime Policy \& Management, 37:4, 377-399.

[10] Monteiro P, de Noronha T, Neto P. (2013) A differentiation framework for maritime clusters: Comparisons across Europe [J]. Sustainability, 5 (9): 4076-4105.
[11] MOHURD, Ministry of Housing and Urban-Rural Development of the PRC. (2015) Energy Efficiency Design Standard for Public Buildings. [GB50189-2015] http://www.mohurd.gov.cn/wjfb/201508/t20150827_224011.h tml.

[12] Porter M E. (1990) The Competitive Advantage of Nations. New York, The Free Press [J]. Competitive Intelligence Review, 1 (1):427.

[13] State Economic and Trade Committee. (2002) Announcement No.36 [2002] Catalog of Eliminating Backward Production Capacity, Process and Product. State Economic and Trade Committee, 02/06/2002. http://www.setc.gov.cn/gjjmwl/200208120030.html. In Chinese.

[14] State Council. (2009) Suggestions No.19 [2009] on Promoting Shanghai's Advanced Manufacturing and Construction of The International Financial and Shipping Center. State Council, $14 / 04 / 2009$.

http://www.gov.cn/xxgk/pub/govpublic/mrlm/200904/t200904 29_33313.html. In Chinese.

[15] Salvador R. Maritime Clusters Evolution. (2014) The (not so) Strange Case of the Portuguese Maritime Cluster [J]. Journal of Maritime Research, 11 (1): 53-59.

[16] Viederyte R. (2013) Maritime cluster organizations: enhancing role of maritime industry development [J]. Procedia-Social and Behavioral Sciences, 81: 624-631.

[17] Weber, A., \& Friedrich, C. J. (1929). Alfred Weber's theory of the location of industries.

[18] Wu Xiaoxia. (2008). Mechanism of Industrial Agglomeration on Labor Mobility - Agglomeration or Dispersion [J]. Northern Economy, 09: 70-71. In Chinese.

[19] Wang, J., Gao, W., Xu, S. Y., \& Yu, L. Z. (2012). Evaluation of the combined risk of sealevel rise, land subsidence, and storm surges on the coastal areas of Shanghai, China. Climatic Change, 115, 537-558.

[20] Wei Zhang \& Jasmine Siu Lee Lam (2013) Maritime cluster evolution based on symbiosis theory and Lotka-Volterra model [J]. Maritime Policy \& Management, 40: 2, 161-176.

[21] Wang X. F., Wu P. C., et al. (2015) New mode for ship lock construction based on Building Information Modeling plus [J]. Port \& Waterway Engineering, 12 (12): 123-127. In Chinese. 